\title{
The distribution of cigarette prices under different tax structures: findings from the International Tobacco Control Policy Evaluation (ITC) Project
}

\author{
Ce Shang, ${ }^{1}$ Frank J Chaloupka, ${ }^{1,2}$ Nahleen Zahra, ${ }^{2}$ Geoffrey T Fong ${ }^{3,4}$
}

${ }^{1}$ Health Policy Center, Institute for Health Research and Policy, University of Illinois at Chicago, Chicago, Illinois, USA 'Department of Economics, University of Illinois at Chicago, Chicago, Illinois, USA ${ }^{3}$ Department of Psychology, University of Waterloo, Waterloo, Canada

${ }^{4}$ Ontario Institute for Cancer Research, Toronto, Ontario, Canada

\section{Correspondence to} Dr Ce Shang, Postdoctoral Research Associate, Health Policy Center, Institute for Health Research and Policy, University of Illinois at Chicago, 1747 W. Roosevelt Rd, Chicago, IL 60608, USA cshang@uic.edu

Received 11 January 2013 Accepted 29 May 2013 Published Online First 21 June 2013

\footnotetext{
To cite: Shang $C$, Chaloupka FJ, Zahra N, et al. Tob Control 2014:23. i23-i29.
}

\begin{abstract}
Background The distribution of cigarette prices has rarely been studied and compared under different tax structures. Descriptive evidence on price distributions by countries can shed light on opportunities for tax avoidance and brand switching under different tobacco tax structures, which could impact the effectiveness of increased taxation in reducing smoking.
\end{abstract}

Objective This paper aims to describe the distribution of cigarette prices by countries and to compare these distributions based on the tobacco tax structure in these countries.

Methods We employed data for 16 countries taken from the International Tobacco Control Policy Evaluation Project to construct survey-derived cigarette prices for each country. Self-reported prices were weighted by cigarette consumption and described using a comprehensive set of statistics. We then compared these statistics for cigarette prices under different tax structures. In particular, countries of similar income levels and countries that impose similar total excise taxes using different tax structures were paired and compared in mean and variance using a two-sample comparison test.

Findings Our investigation illustrates that, compared with specific uniform taxation, other tax structures, such as ad valorem uniform taxation, mixed (a tax system using ad valorem and specific taxes) uniform taxation, and tiered tax structures of specific, ad valorem and mixed taxation tend to have price distributions with greater variability. Countries that rely heavily on ad valorem and tiered taxes also tend to have greater price variability around the median. Among mixed taxation systems, countries that rely more heavily on the ad valorem component tend to have greater price variability than countries that rely more heavily on the specific component. In countries with tiered tax systems, cigarette prices are skewed more towards lower prices than are prices under uniform tax systems. The analyses presented here demonstrate that more opportunities exist for tax avoidance and brand switching when the tax structure departs from a uniform specific tax.

\section{INTRODUCTION}

Significant increases in cigarette excise taxes have been shown to be the most effective policy for reducing smoking. ${ }^{1}$ Tobacco excise taxes can be levied in two forms: specific and ad valorem taxes. A specific excise tax is a monetary tax levied based on the quantity of tobacco products (eg, per pack or by weight). While an ad valorem excise tax is a tax levied as a percentage of the value of tobacco products (eg, manufacturer's price or retail price). ${ }^{2}$
Although most governments impose certain excise taxes on cigarettes, the structure of these taxes varies markedly by countries. For instance, while many high-income countries (HICs) rely solely on specific excise taxes on cigarettes, European Union (EU) countries are required by the Council of the EU to impose excise taxes consisting of specific and ad valorem components, with a minimum floor. In addition, individual EU countries decide on the share of each component in total taxes under rules stating that the specific component must be between $5 \%$ and $76.5 \%$ of the total tax share of the weighted average price of cigarettes. ${ }^{2}{ }^{3}$ As a result, individual EU countries rely differently on the specific and ad valorem components of their total cigarette excise tax.

On the other hand, excise tax structures in lowincome and middle-income countries (LMICs) are often more diverse than those in HICs. Unlike HICs where many non-EU countries employ a uniform specific tax system, a large number of LMICs impose ad valorem or mixed excise taxes on cigarettes. In addition, the tax structure may vary with the rates levied on cigarettes differing with the characteristics of the cigarette, such as retail and manufacturer's price level, length or presence/absence of a filter, and/or with the characteristics of the producer, such as output. For example, China imposes tiered taxes based on manufacturer's price level and, until July 2010, Egypt levied tiered specific excises based on ex-factory prices of cigarettes. ${ }^{\text {i. }}{ }^{4}$ In addition to these rules, many countries impose a minimum specific tax floor as well, with a few exceptions such as Russia, where the minimum tax floor is applied to the ad valorem and specific components. In general, cigarette excise tax structures can be grouped into categories of specific taxes only, ad valorem taxes only and the mixture of both taxes. Alternatively, any tax structure can be grouped according to whether it levies uniform or tiered taxes. According to a report by the $\mathrm{WHO}$ that documents the tax structure of 182 countries, other than the 19 countries where excise tobacco taxes have not yet been imposed, 55 countries employ a purely specific tax system, 60 countries use a purely ad valorem system and 48 use a mixed tax system. ${ }^{2}$

Despite these various excise tax systems, there is a lack of empirical evidence on how cigarette

${ }^{\mathrm{i}} \mathrm{Ex}$-factory price means the price at the factory, and does not include any other charges, such as delivery costs or taxes imposed later in the distribution chain. 
prices, through which taxation ultimately impacts smoking, are distributed in different systems. In particular, for LMICs where smoking is prevalent, the importance of tax structure as a factor mediating the effectiveness of tobacco taxation in controlling tobacco use has rarely been studied or discussed. For example, recent studies from China suggest that cigarette demand is relatively unresponsive to price, which might be a result of China's complicated tiered tax structure that results in very low prices for some brands. ${ }^{5} 6$ Therefore, it is important to understand how cigarette prices are associated with tax structures in order to maximise the impact of tobacco taxation on tobacco use.

From an economic perspective, given that the cigarette market is usually dominated by a small number of companies in most countries, cigarette price distributions may largely depend on taxation systems. Economic models have implied that, compared with specific excises, ad valorem excises tend to lead to lower prices and may encourage trading down, for example, the purchase of cheaper cigarettes. ${ }^{2}$ This is because an ad valorem tax structure creates incentives for manufacturers to produce low quality, low price cigarettes. In contrast, specific excises, in the form of taxes or a tax floor, tend to lead to higher prices, in that producers have incentives to raise prices when they can claim all the increased revenue (which is not the case for ad valorem excises). In addition, specific excises would reduce consumers' incentives to switch down when taxes increase by raising the relative price of lower-price to higher-price brands. In their examination of cigarette prices in 21 EU countries, Chaloupka $e t a l^{7}$ find that the price gap between premium and low-priced brands is smaller in countries with a greater specific component to excise taxes. However, that study is based on empirical evidence from EU countries that all use mixed taxation systems with different shares of specific and ad valorem taxes and, as a result, cannot directly compare pure specific, pure ad valorem and mixed systems, or tiered and uniform systems. Moreover, the price gap in that study is based on prices collected by the Economists Intelligence Unit for one leading international brand and one leading local brand, thus not reflecting the full distribution of cigarette prices in the market. Meanwhile, other than the aforementioned reasons, if the relative price of lower-priced brands relative to higher-priced brands increases, the market share of low-priced brands will likely fall. Therefore, compared with ad valorem excises, specific excises might lead to even higher prices with less price variability. The empirical evidence on the former hypothesis is shown in studies using data from HICs with purely specific tax systems. Nargis et $a l^{8}$ used four waves of data from the International Tobacco Control Policy Evaluation (ITC) Surveys in Canada and the USA to examine the association between brand choice and relative prices and found that an increase in the relative price of lower-priced to higher-priced brands is associated with a decrease in purchasing of lower-priced brands in both countries. Sobel and Garrett ${ }^{9}$ also found that increases in the specific taxes in the USA lead to a lower market share for lower-priced generic brands.

Likewise, a taxation system that levies uniform tax rates, compared with differential rates based on brand characteristics, may reduce switching down and the incentive for manufacturers to reduce tax liabilities through their pricing strategies. ${ }^{2}$ In sum, it is likely that greater reliance on more complicated tax structures than uniform specific taxation is associated with a smaller price ratio of lower-price to higher-price brands and wider price distribution, which can allow for more tax avoidance and switching down. ${ }^{10-14}$ Moreover, some recent studies constructed survey-derived cigarette prices using Global Adult Tobacco
Survey (GATS) data from LMICs and showed that cigarette prices are widely distributed in these countries, indicating that complicated tax structures in LMICs could be a factor that broadens the price gap. ${ }^{15} 16$

Several factors other than tax structures, such as tax avoidance and tax evasion, are likely to shape the cigarette price distribution as well. In some countries, taxes on tobacco are levied differently across jurisdictions such as states, provinces and Indian reservations. Therefore, cross-national-border and cross-jurisdiction-border shopping is one way to avoid taxes. For instance, in Canada and the USA, some excise taxes are exempted in aboriginal reserves and Native American reservations. $^{1}$ In a recent paper Merriman ${ }^{17}$ assessed the extent of avoidance/evasion by collecting littered cigarette packs around Chicago, and found that three-fourths of the packs collected in Chicago did not bear the Chicago tax stamp. Using data from 15 ITC countries, Guindon et al ${ }^{18}$ found that more than $10 \%$ of smokers report engaging in tax avoidance or tax evasion in Canada, the UK and Malaysia.

Tax evasion, such as large-scale smuggling, could also contribute to an increase in the share of low-priced cigarettes. Although there is insufficient evidence that large-scale smuggling lowers average retail prices, some research has indicated that illicit trade could burden low-income countries disproportionately, where illicit cigarettes constitute $16.8 \%$ of the market compared with $9.8 \%$ of the market in HICs. ${ }^{19}$ The cigarette prices that we examine in this paper are survey-derived prices that reflect the combined effects of tax structures, tax avoidance and tax evasion. Although it is impossible in this study to disentangle the contribution of each to the distribution of cigarette prices, we hypothesise that the tax structure plays the most important role in cross-country differences in the price distribution. Moreover, unlike tax evasion and tax avoidance by switching to cheaper cigarettes, which may have a greater effect on prices at the lower end, differences in tax structures would have an effect in shifting the overall distribution of cigarette prices.

In summary, a greater price gap among brands could reduce the effectiveness of taxation in reducing tobacco use by increasing opportunities for substitution to cheaper brands as taxes rise. Among many tax structures, the uniform specific tax structure simplifies the taxation system and has advantages in raising the average prices and the relative price of lower-priced to higher-priced cigarettes. As a result, a uniform tax structure can increase the effectiveness of tax increases in reducing smoking. ${ }^{1}$ Therefore, analysing the price distribution using survey-derived data will add to the empirical evidence on how price distributions and gaps differ under alternative tax structures. Tax structures that lead to higher average prices and smaller price gaps can lead to a more effective tax system for reducing smoking. In this paper, we use data taken from 16 countries of the ITC Project, which cover many types of tax structures, to describe and compare cigarette price distributions across different tax structures.

\section{DATA AND METHODOLOGY}

Cigarette prices were derived for each country using the most recent data from the ITC Project Surveys. ${ }^{\text {ii }}$ The ITC Project consists of parallel longitudinal surveys of smokers and other

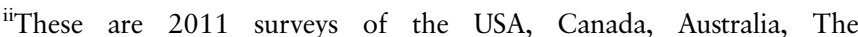
Netherlands, Germany, Uruguay, Mauritius and Mexico; 2010 surveys of the Republic of Korea, the UK and Bangladesh; 2009 surveys of Brazil, Malaysia, Thailand and China; and the 2008 Survey of France. 
tobacco users (and non-users in most countries) conducted in 22 countries inhabited by more than $50 \%$ of the world's population, $60 \%$ of the world's smokers and $70 \%$ of the world's tobacco users. The ITC Surveys are designed to evaluate the policies of the WHO Framework Convention on Tobacco Control. ${ }^{20}$ For the analyses reported in this paper, we selected ITC countries where cigarette purchase information was collected from smokers. The price per pack of 20 cigarettes was thereafter derived from the money spent in the last purchase and the number of cigarettes that were bought. ${ }^{\text {iii }}$ In order to compare prices and their distributions across countries, we converted the derived prices in local currencies into constant 2010 international dollars using the purchasingpower parity and consumer price index of the country. Purchasing-power parity conversion factors and the consumer price index for each country were obtained from the International Monetary Fund World Economic Outlook database. In order to reflect the market share of cigarettes at different price levels, we use consumption weights to obtain aggregated measures of cigarette prices. Namely, for each individual smoker, we calculate how many cigarettes they smoke per day and construct a consumption weight as the ratio of his or her own consumption to the total consumption of respondents to the survey. These consumption weights are applied to cigarette prices when reporting mean, median and quartile prices.

Survey-derived prices are likely to better reflect the price distribution in the market than are other sources of prices, especially when we are interested in comparing the price distribution under different tax systems. ${ }^{21}$ These comparisons shed some light on the association between tax structure and price distribution, and resulting opportunities for tax avoidance under different structures. As discussed above, the tax structure could be exclusively specific, ad valorem, or a mixture of the two. Alternatively, taxes can also be levied uniformly or by tiers. Economic reasoning implies that tax structures with tiers or that rely more heavily on ad valorem excises will yield more opportunities for tax avoidance and branch switching. In the ITC Project sample of countries, a majority rely on uniform taxes, with only Brazil, Republic of Korea, China and Bangladesh applying tiered taxes. Most non-EU HICs including the USA, Canada, Australia and Republic of Korea, and some LMICs including Brazil, Uruguay and Mauritius solely rely on specific excises. In contrast, Bangladesh and Thailand rely on purely ad valorem excises; and China, Malaysia and EU countries apply mixed systems of specific and ad valorem excises, while individual countries may largely rely on one of the components.

We collected detailed information on tax structures including the type of structure (exclusively specific, exclusively ad valorem, and mixed structure, with either uniform or tiered rates), the shares of the specific and ad valorem component among total excises ${ }^{\text {iv }}$, and the amount of specific and ad valorem excises on a pack of 20 cigarettes in each country over years from a variety of sources ${ }^{\mathrm{v}}$. The majority of the tax

\footnotetext{
iii The cigarette price is derived from price per carton, price per pack, price per stick and the number of cigarettes in each carton or pack.

${ }^{\text {iv }}$ Throughout the paper, total excises do not include value added taxes (VATs). The amount of ad valorem taxes in China were imputed using the weighted average retail cigarette prices and average VAT and ad valorem tax rates reported in China Statistical Yearbook. The ad valorem tax in Thailand, Malaysia, Mexico and Bangladesh were imputed using ad valorem tax and VAT rates and average cigarette prices. Ad valorem taxes in EU countries were imputed using the ratio of ad valorem to specific components and the amount of specific taxes. ${ }^{\mathrm{v}}$ From this point, taxes refer to the taxes for a pack of 20 cigarettes.
}

information was obtained from a series of reports produced by the Bloomberg Global Initiative to Reduce Tobacco Use ${ }^{\text {vi }}$, Euro-monitor International's country specific reports ${ }^{\mathrm{vii}}$, the WHO Tobacco Free Initiative's periodic reports on the global tobacco epidemic viii and government reports of tobacco excise taxes. The excise information for EU countries came from the Excise Duty Tables constructed by the European Commission. The excise information for Australia came from VicHealth Center for Tobacco Control. The excise information for the US was obtained from tax burden on tobacco by Orzechowski and Walker and is inclusive of federal and average state excise taxes. ${ }^{22}$ The tax information of Canada came from The Nova Scotia Provincial Tax Commission and is a population weighted average of the federal and provincial taxes. The type of structure for all countries in recent years has also been documented in the tax administration published by the WHO. ${ }^{2}$

The analyses in this paper proceed as follows: In table 1, after ranking countries by tax structure, the percentage of the specific component among the total excise tax, and the amount of total excise taxes, we present comprehensive statistics for price distribution by countries. In particular, mean, median, SD and skewness of prices are reported to show how much prices are skewed towards lower prices under alternative tax structures. The first quartile, third quartile and IQR, which is measured by the difference between the first and third quartile, are also reported. In addition, we calculate and show the ratio of the IQR to the median, which shows price variability around the median price. Other important statistics such as the minimum price, maximum price, price range and the ratio of the price range to the mean are also shown in table 1 . Also, in figure 1 , we exhibit price distributions by countries using boxplot to visualise the statistics that are reported in table 1 and to present the price distribution and variability in one graph. In table 2 we show, by tax structure, countries where prices are skewed in different directions and those where prices are most heavily skewed (skewness statistics are greater than 1 or smaller than -1). Finally, in table 3 we select and pair countries that are close in income levels and in the amount of total excise tax but that employ different tax structures, in order to compare their mean and variance using a two-sample comparison test.

\section{RESULTS}

In table 1 , we categorise countries by their tax structures and the percentage of specific taxes among total excise taxes; VATs are excluded. Among countries with a mixed uniform tax structure, The Netherlands has the largest share of the specific component while France has the smallest (range: 9.4-67.3\%). Although China imposes a small specific excise, the system largely relies on the tiered ad valorem component. And in general, for countries that impose a similar amount of total excises, those with simpler tax structures tend to have higher average prices. For instance, Mauritius and Mexico impose total excises of $\$ 2.45$ and $\$ 2.29$, respectively, but the mean price for Mauritius which uses a uniform specific tax structure is $\$ 1.29$ higher than Mexico where a mixed tax structure is used. Among EU countries, The Netherlands and France impose total excises of $\$ 3.37$ and $\$ 3.80$, respectively, while The Netherlands with a larger specific share has a mean price \$0.49 higher than France, which has a larger ad valorem share. The skewness statistics

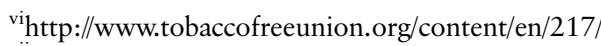

vii http://www.euromonitor.com/

viiihttp://www.who.int/tobacco/
} 
Table 1 Summary statistics of the price distribution of cigarettes by International Tobacco Control Policy Evaluation (ITC) countries with different tax structures

\begin{tabular}{|c|c|c|c|c|c|c|c|c|c|c|c|c|c|c|c|c|}
\hline \multirow{3}{*}{$\begin{array}{l}\text { Tax structure* } \\
\text { Tax structuret } \\
\text { Country }\end{array}$} & \multicolumn{7}{|c|}{ Specific } & \multicolumn{7}{|l|}{ Mixed } & \multicolumn{2}{|c|}{ ad valorem } \\
\hline & \multicolumn{5}{|c|}{ Uniform } & \multicolumn{2}{|l|}{ Tiered } & \multicolumn{6}{|c|}{ Uniform } & \multirow{2}{*}{$\begin{array}{l}\text { Tiered } \\
\text { RC }\end{array}$} & \multirow{2}{*}{$\begin{array}{l}\text { Uniform } \\
\text { TH }\end{array}$} & \multirow{2}{*}{$\begin{array}{l}\text { Tiered } \\
\text { BD }\end{array}$} \\
\hline & $A U$ & CA & MU & US & UY & KR & BR & NL & MY & UK & $\mathrm{DE}$ & $M X$ & FR & & & \\
\hline Mean & 6.52 & 5.41 & 5.65 & 4.49 & 2.75 & 3.10 & 2.24 & 5.62 & 4.79 & 7.49 & 5.29 & 4.36 & 5.13 & 1.98 & 3.02 & 1.42 \\
\hline Median & 6.44 & 5.69 & 5.54 & 4.37 & 3.18 & 3.13 & 1.98 & 5.73 & 5.17 & 7.75 & 5.58 & 4.33 & 5.37 & 1.51 & 2.78 & 1.41 \\
\hline SD & 1.00 & 1.78 & 0.89 & 1.62 & 1.06 & 0.78 & 1.40 & 0.94 & 1.34 & 2.00 & 1.20 & 1.24 & 1.17 & 1.55 & 0.92 & 0.86 \\
\hline Skewness & -0.44 & -0.42 & 0.75 & 1.37 & -0.31 & 8.24 & 5.21 & -0.07 & -0.96 & -0.29 & -1.17 & 1.51 & -0.82 & 3.61 & 0.19 & 2.01 \\
\hline Q1 & 5.85 & 4.42 & 4.99 & 3.55 & 1.85 & 3.13 & 1.65 & 5.20 & 4.34 & 6.93 & 4.90 & 3.65 & 5.15 & 1.13 & 2.28 & 0.70 \\
\hline Q3 & 7.18 & 6.56 & 5.54 & 5.24 & 3.70 & 3.13 & 2.44 & 5.97 & 5.50 & 8.73 & 6.08 & 4.33 & 5.82 & 2.47 & 3.70 & 1.93 \\
\hline $\mathrm{IQR}=\mathrm{Q} 3-\mathrm{Q} 1$ & 1.33 & 2.13 & 0.55 & 1.70 & 1.85 & 0 & 0.79 & 0.77 & 1.16 & 1.81 & 1.18 & 0.68 & 0.67 & 1.35 & 1.42 & 1.23 \\
\hline IQR/median & 0.21 & 0.37 & 0.10 & 0.39 & 0.58 & 0 & 0.40 & 0.13 & 0.22 & 0.23 & 0.21 & 0.16 & 0.12 & 0.89 & 0.51 & 0.87 \\
\hline Minimum & 0.68 & 0.40 & 1.11 & 0.50 & 0.34 & 1.50 & 0.66 & 1.05 & 0.52 & 0.37 & 0.12 & 0.91 & 0.67 & 0.03 & 0.19 & 0.04 \\
\hline Maximum & 12.4 & 13.3 & 11.1 & 19.4 & 5.29 & 12.5 & 13.2 & 12.6 & 11.5 & 19.6 & 7.75 & 11.4 & 12.6 & 17.6 & 6.17 & 10.5 \\
\hline Maximum-Minimum & 11.7 & 12.9 & 9.97 & 18.9 & 4.95 & 11.0 & 12.6 & 11.6 & 11.0 & 19.3 & 7.63 & 10.5 & 11.9 & 17.6 & 5.98 & 10.5 \\
\hline $\begin{array}{l}\text { Maximum-Minimum/ } \\
\text { mean }\end{array}$ & 1.79 & 2.38 & 1.76 & 4.21 & 1.80 & 3.55 & 5.63 & 2.06 & 2.30 & 2.58 & 1.44 & 2.41 & 2.32 & 8.87 & 1.98 & 7.39 \\
\hline Specific taxes & 4.27 & 3.67 & 2.45 & 2.41 & 2.00 & 1.65 & 0.52 & 2.27 & 1.15 & 3.11 & 1.95 & 0.80 & 0.36 & 0.02 & 0 & 0 \\
\hline Ad valorem taxes & 0 & 0 & 0 & 0 & 0 & 0 & 0 & 1.10 & 0.70 & 1.97 & 1.44 & 1.49 & 3.44 & 0.54 & 1.98 & 0.45 \\
\hline Total taxes & 4.27 & 3.67 & 2.45 & 2.41 & 2.00 & 1.65 & 0.52 & 3.37 & 2.25 & 5.08 & 3.39 & 2.29 & 3.80 & 0.56 & 1.98 & 0.45 \\
\hline$\%$ specific of total & 100 & 100 & 100 & 100 & 100 & 100 & 100 & 67.3 & 62.1 & 61.2 & 57.5 & 34.9 & 9.42 & 2.94 & 0 & 0 \\
\hline
\end{tabular}

show that in countries where tiered taxes are applied, prices are more likely positively skewed, indicating that there are fewer higher prices in the distribution. In contrast, most countries with a uniform tax structure have skewness statistics close to 0 , suggesting prices are relatively symmetric. When comparing Malaysia and Mexico, where a mixed structure is applied in both cases but Malaysia has a larger share of the specific tax component, more prices in Mexico are lower while more prices in Malaysia are higher.
The ratio of the IQR to the median reported in table 1 shows how prices deviate around the median. In countries with a purely ad valorem tax system, such as Bangladesh and Thailand, and China, which largely employs ad valorem taxation, this ratio is as high as $0.51-0.89$, which suggests greater price variability around median prices. On the other hand, other than Uruguay, the USA and Canada where cross-jurisdiction shopping opportunities are relatively available, countries with mixed and specific uniform structures tend to have prices that vary less
Figure 1 Boxplot of cigarette price distributions by country. AU (Australia), CA (Canada), MU (Mauritius), US (the USA), UY (Uruguay), KR (Republic of Korea), BR (Brazil), NL (The Netherlands), MY (Malaysia), UK (the UK), DE (Germany), MX (Mexico), FR (France), RC (China), TH (Thailand) and BD (Bangladesh).

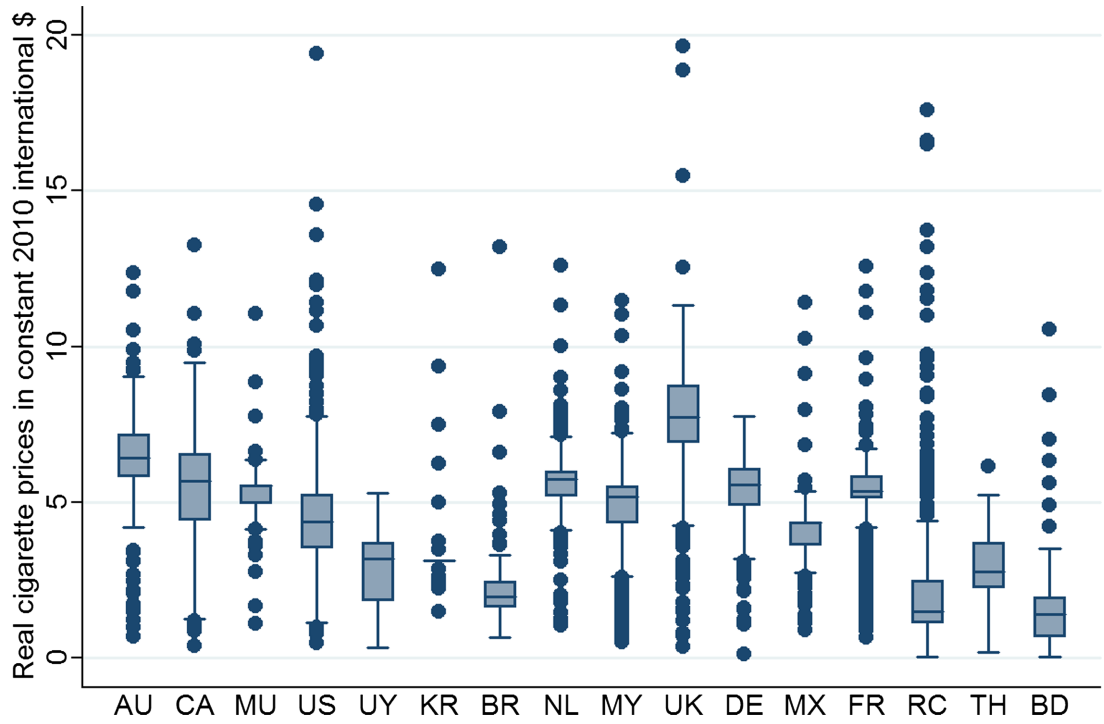


Table 2 Countries by tax structure, mean and median comparison, and skewness

\begin{tabular}{lll}
\hline & Mean>Median & Mean<Median \\
\hline Specific $(\mathrm{N}=7)$ & USA, Mauritius, Australia, Brazil & Uruguay, Canada, Republic of Korea, \\
Mixed $(\mathrm{N}=7)$ & Mexico, China & The Netherlands, Malaysia, UK, Germany, France \\
Ad valorem $(\mathrm{N}=2)$ & Bangladesh, Thailand & \\
Uniform $(\mathrm{N}=12)$ & USA, Mauritius, Australia, Mexico, Thailand & Uruguay, The Netherlands, Malaysia, UK, Germany, France \\
Tiered $(\mathrm{N}=4)$ & Brazil, China, Bangladesh & Republic of Korea \\
& Skewness>1 & Skewness $<-1$ \\
Specific $(\mathrm{N}=7)$ & USA, Republic of Korea, Brazil & - \\
Mixed $(\mathrm{N}=7)$ & China, Mexico & Germany \\
ad valorem ( $=2)$ & Bangladesh & - \\
Uniform $(\mathrm{N}=12)$ & USA, Mexico & Germany \\
Tiered $(\mathrm{N}=4)$ & Republic of Korea, Brazil, China, Bangladesh & - \\
\hline
\end{tabular}

Tax structures were first grouped to three categories: specific, ad valorem and a mixed structure of the two, and then to two categories: uniform and tiered.

around the median, with ratios less than 0.25 . When looking into the price range measured by the distance between the maximum and minimum prices, there is no clear pattern by different structures. However, if we compare how great the range is in contrast to the mean, the results indicate that the range is six to nine times as large as the mean in Bangladesh, China and Brazil, where taxes are levied by tiers, while other countries have ratios in the range of $1-4$. In addition, China has a price range of $\$ 17.6$, which is extremely wide compared with its average price.

Table 2 summarises countries by comparing mean and median prices, as well as the skewness of prices. In the upper panel, we report countries where the mean price is higher than the median and those where the price mean is lower than the median, respectively. In contrast to the median, a higher mean suggests a positively-skewed price distribution that prices

Table 3 Comparison tests of cigarette prices in selected countries by different tax structures

\begin{tabular}{|c|c|c|c|c|c|c|c|c|}
\hline \multirow{2}{*}{$\begin{array}{l}\text { LMICs } \\
\text { Countries }\end{array}$} & \multicolumn{2}{|c|}{$\begin{array}{l}\text { Specific uniform vs } \\
\text { specific tiered }\end{array}$} & \multicolumn{2}{|c|}{$\begin{array}{l}\text { Specific uniform vs } \\
\text { mixed uniform }\end{array}$} & \multicolumn{2}{|c|}{$\begin{array}{l}\text { Mixed uniform vs ad } \\
\text { valorem uniform }\end{array}$} & \multicolumn{2}{|c|}{$\begin{array}{l}\text { Mixed-specific vs } \\
\text { Mixed-ad valorem, } \\
\text { Uniform }\end{array}$} \\
\hline & UY & BR & MU & $\mathrm{MX}$ & MY & TH & MY & $\mathrm{MX}$ \\
\hline Mean & 2.748 & 2.512 & 5.898 & 4.795 & 4.894 & 3.142 & 4.894 & 4.795 \\
\hline SD & $(1.058)$ & $(1.130)$ & $(1.081)$ & $(1.551)$ & (1.355) & $(0.917)$ & (1.355) & (1.551) \\
\hline $\mathrm{N}$ & 1014 & 212 & 530 & 1739 & 1712 & 937 & 1712 & 1739 \\
\hline Variation comparison test & \multicolumn{2}{|c|}{$\begin{array}{l}\text { H0: } S D(U Y) / S D(B R)>1 \\
F=0.56 ; P=0.00 \\
D F=1013,211 \\
H 0 \text { rejected }\end{array}$} & \multicolumn{2}{|c|}{$\begin{array}{l}\mathrm{H} 0: \mathrm{SD}(\mathrm{MU}) / \mathrm{SD}(\mathrm{MX})>1 \\
\mathrm{~F}=0.49 ; \mathrm{P}=0.00 \\
\mathrm{DF}=529,1738 \\
\text { H0 rejected }\end{array}$} & \multicolumn{2}{|c|}{$\begin{array}{l}\text { HO: } S D(M Y) / S D(T H)> \\
F=2.18 ; P=1.00 \\
D F=1711,936 \\
\text { HO not rejected }\end{array}$} & \multicolumn{2}{|c|}{$\begin{array}{l}\mathrm{H} 0: \mathrm{SD}(\mathrm{MY}) / \mathrm{SD}(\mathrm{MX})>1 \\
\mathrm{~F}=0.76 ; P=0.00 \\
\mathrm{DF}=1711,1738 \\
\mathrm{H} 0 \text { rejected }\end{array}$} \\
\hline Mean comparison test & \multicolumn{2}{|c|}{$\begin{array}{l}\text { H0: Mean }(U Y)-(B R)<0 \\
T=2.30 ; P=0.01 \\
D F=263 \\
\text { H0 rejected }\end{array}$} & \multicolumn{2}{|c|}{$\begin{array}{l}\text { H0: Mean }(M U)-(M X)<0 \\
T=18.4 ; P=0.00 \\
D F=1252 \\
\text { H0 rejected }\end{array}$} & \multicolumn{2}{|c|}{$\begin{array}{l}\text { H0: Mean (MY)-(Tr } \\
T=39.5 ; P=0.00 \\
D F=2531 \\
\text { H0 rejected }\end{array}$} & \multicolumn{2}{|c|}{$\begin{array}{l}\text { H0: Mean }(M Y)-(M X)<0 \\
T=2.0 ; P=0.02 \\
D F=3401 \\
\text { H0 rejected }\end{array}$} \\
\hline HICs & \multicolumn{2}{|c|}{$\begin{array}{l}\text { Specific uniform vs mixed } \\
\text { uniform }\end{array}$} & \multicolumn{2}{|c|}{$\begin{array}{l}\text { Specific uniform vs mixed } \\
\text { uniform }\end{array}$} & \multicolumn{2}{|c|}{$\begin{array}{l}\text { Mixed-specific vs } \\
\text { mixed-ad valorem, } \\
\text { uniform }\end{array}$} & \multicolumn{2}{|c|}{$\begin{array}{l}\text { Mixed-specific vs } \\
\text { Mixed-ad valorem, } \\
\text { Uniform }\end{array}$} \\
\hline Countries & $\mathrm{AU}$ & UK & $\mathrm{AU}$ & FR & NL & FR & NL & $\mathrm{DE}$ \\
\hline Mean & 6.611 & 7.634 & 6.611 & 5.133 & 5.613 & 5.133 & 5.613 & 5.336 \\
\hline SD & $(1.179)$ & $(1.966)$ & (1.179) & $(1.212)$ & $(0.849)$ & $(1.212)$ & $(0.849)$ & (1.195) \\
\hline $\mathrm{N}$ & 869 & 592 & 869 & 1322 & 968 & 1322 & 968 & 383 \\
\hline Variation comparison test & \multicolumn{2}{|c|}{$\begin{array}{l}\mathrm{H} 0: \mathrm{SD}(\mathrm{AU}) / \mathrm{SD}(\mathrm{UK})>1 \\
\mathrm{~F}=0.36 ; \mathrm{P}=0.00 \\
\mathrm{DF}=868,591 \\
\mathrm{H} 0 \text { rejected }\end{array}$} & \multicolumn{2}{|c|}{$\begin{array}{l}\text { H0: SD }(A U) / S D \\
F=0.95 ; P=0.19 \\
D F=868,1321 \\
\text { HO not rejected }\end{array}$} & \multicolumn{2}{|c|}{$\begin{array}{l}\mathrm{H} 0: \mathrm{SD}(\mathrm{NL}) / \\
\mathrm{F}=0.40 ; \mathrm{P}=0 . \\
\mathrm{DF}=967,132 \\
\text { H0 rejected }\end{array}$} & \multicolumn{2}{|c|}{$\begin{array}{l}\mathrm{H} 0: \mathrm{SD}(\mathrm{NL}) / \mathrm{SD}(\mathrm{DE})>1 ; \\
\mathrm{F}=0.51 ; \mathrm{P}=0.00 \\
\mathrm{DF}=967,382 \\
\mathrm{H} 0 \text { rejected }\end{array}$} \\
\hline Mean comparison test & \multicolumn{2}{|c|}{$\begin{array}{l}\text { H0: Mean }(A U)-(U \\
T=-11.3 ; P=1.00 \\
D F=880 \\
\text { H0 not rejected }\end{array}$} & \multicolumn{2}{|c|}{$\begin{array}{l}\text { H0: Mean }(\mathrm{AU})-(\mathrm{FR})<0 \\
\mathrm{~T}=28.2 ; \mathrm{P}=0.00 \\
\mathrm{DF}=2189 \\
\text { H0 rejected }\end{array}$} & \multicolumn{2}{|c|}{$\begin{array}{l}\text { H0: Mean }(N L)-(F R)<0 \\
T=11.1 ; P=0.00 \\
D F=2284 \\
\text { H0 rejected }\end{array}$} & \multicolumn{2}{|c|}{$\begin{array}{l}\text { H0: Mean }(\mathrm{NL})-(\mathrm{DE})<0 \\
\mathrm{~T}=4.14 ; \mathrm{P}=0.00 \\
\mathrm{DF}=541 \\
\text { H0 rejected }\end{array}$} \\
\hline
\end{tabular}

Prices were unweighted when conducting two-sample comparison test. Mean comparison tests were performed by allowing the variance of the two sample to be different. When unequal population variances of prices were detected for studied counties, Satterthwaite's degrees of freedom that accommodate the unequal variances are reported instead of usual ones. Mixed-specific represents the country where the share of specific excise component is greater than their paired country in the comparison. And mixed-ad valorem represents the country where the share of ad valorem excise component is greater than their paired country in the comparison.

HICs, high-income countries; LMICs, low-income and middle-income countries. 
concentrate at lower values; and a lower mean suggests the opposite. These measures show that among the seven countries with the purely specific tax structure, four countries have mean prices larger than the median and three have mean prices smaller than the median. However, the mean and median prices are very close in magnitude for most countries with a specific tax structure. The skewness statistics reported in the lower panel show that prices are largely skewed to lower values in China, Brazil, Mexico, Bangladesh and Republic of Korea, where either tiered or ad valorem taxes (ad valorem component in mixed structures) are applied. This finding suggests that tiered and ad valorem taxes may distort cigarette prices towards lower values, increasing opportunities for switching to cheaper cigarettes as tax increases. In addition, prices are heavily skewed to lower values in the USA, which might reflect tax avoidance by crossjurisdiction shopping.

Finally, we select and pair countries that are close in the amount of total excise taxes but that use different tax structures, to compare their mean and variance using a two-sample comparison test. The selected country pairs are as follows: for LMICs, Uruguay (specific uniform) and Brazil (specific tiered) are paired to compare uniform and tiered tax structures; Mauritius (specific uniform) and Mexico (mixed uniform) are paired to compare specific and mixed structures; Malaysia and Thailand are paired to compare mixed and ad valorem uniform structures; and Malaysia and Mexico are paired to compare mixed structures with different shares of specific components. For HICs, Australia and the UK/France are paired to compare specific and mixed uniform structures. In addition, The Netherlands and France/Germany are paired to compare mixed systems dominated by specific and ad valorem components, respectively. The hypotheses that more complicated tax structures tend to have a higher price mean and present a smaller price variance are tested, with the rejection of these hypotheses suggesting the opposite. The results of the twosample mean and SD (variance) comparison tests are shown in table 3 .

Although the mean comparison tests do not reject the hypothesis for one set of paired countries (Australia vs the UK), the remainder do. The rejection of this hypothesis for a majority of the comparisons indicates that countries where tax systems are simpler tend to have higher average prices than countries that impose similar total excise amounts but that have more complicated tax systems. The two-sample SD comparison tests of prices within each development group (HICs vs LMICs) yield similar results: cigarette prices show greater variability in countries where tax structures are more complicated. For example, the specific tiered system of Brazil has a higher SD than the specific uniform system of Uruguay. In particular, when comparing within the uniform tax structure, the mixed system of Mexico has a higher SD than the specific system of Mauritius, and the same conclusion holds for the SD comparison between Australia and the UK. Although the SD comparison of Australia and France suggests the SDs of the two countries are about the same, Australia has a much higher mean price than France. The mixed system of Malaysia has a higher price SD than the pure ad valorem system of Thailand, which suggests that mixed system in LMICs may not be superior to a pure ad valorem system in lowering price variability. The mixed system of France, which relies heavily on the ad valorem component, has a higher SD than The Netherlands, which relies heavily on the specific component. The same conclusions are found when comparing The Netherlands with
Germany and Malaysia with Mexico. In sum, more complicated taxation systems tend to have greater price variability, and therefore are likely to provide more opportunities for tax avoidance by brand switching.

\section{DISCUSSION AND LIMITATION}

In this paper, we employed data for 16 countries taken from the ITC Project to construct survey-derived cigarette prices for each country. These self-reported prices were weighted by cigarette consumption and described using a comprehensive set of statistics. We further compared these statistics for cigarette prices under different tax structures. In particular, countries that are close in the amount of total excise taxes but that impose different tax structures were paired and compared in mean and variance using a two-sample comparison test.

There are a few limitations to these analyses. First, we presented direct evidence of price distribution in countries where different taxation systems are imposed. However, we did not estimate or analyse the associations between the type of tax structure and measures of the price distribution. Therefore, we cannot conduct a formal test of these associations. In addition, tax structures were grouped using two characteristics: the component of specific and ad valorem excise taxes, and if tiered rates are levied. As a result, it is difficult to disentangle the extent to which tiered and ad valorem tax structures distort the price distribution. Finally, we did not explicitly control for various forms of tax avoidance or evasion, such as cross-border shopping. Further research using times series data from many countries with different and changing tax structures is needed to address these limitations.

Our investigation illustrates that, compared with uniform specific taxation, other uniform tax structures (ad valorem uniform and mixed uniform structures) tend to have price distributions with greater variability. Also, compared with uniform taxation, tiered tax structures tend to have price distributions with greater variability. Countries that rely heavily on ad valorem and tiered taxes generally have greater variability in prices around the median. Among mixed taxation systems, countries that rely more heavily on the ad valorem component tend to have greater variability in prices than countries that rely more heavily on the specific component. Among different tax structures that impose similar total excise taxes, simpler structures tend to have higher price means. In countries with tiered tax systems, cigarette prices are more skewed to lower prices than prices under uniform systems.

The analyses presented here demonstrate that when the tax structure departs from uniform specific taxes, more opportunities exist for tax avoidance by switching down to cheaper brands. These results also provide a potential explanation for why smokers in countries with a complicated tax structure, such as China, are often found to be relatively unresponsive to cigarette prices. In light of our findings, countries that solely rely on ad valorem excises would see tax increases have a greater impact on tobacco use if they were to switch to a pure specific taxation system. Similarly, for countries with a mixed taxation system such as Mexico, Malaysia and EU countries, increasing the share of the specific component or switch to a pure specific taxation system would enhance the effectiveness of the tax in reducing tobacco use. Finally, our findings indicate that tax structures have a substantial impact on price variability in cigarette markets, thus likely impacting smoking behaviours, including prevalence, consumption and cessation. Future research should explore how tax structures affect these smoking behaviours. 


\section{What this paper adds}

- Economic models have suggested that a simple taxation system that applies a uniform specific excise tax has advantages in raising average cigarette prices, reducing tax avoidance and switching down, and discouraging manufacturer's incentives for pricing strategies that lower market prices. However, there is insufficient empirical evidence on how prices are distributed under different tax structures.

- In this paper, we present and compare price distributions under alternative tax structures. We find that, compared with a uniform specific tax structure, tiered structures and other uniform tax structures tend to have price distributions with greater variability.

- Among mixed taxation systems, countries that rely more heavily on the ad valorem component of the total tax tend to have greater price variability than countries that rely more heavily on the specific component.

- In countries with tiered tax systems, cigarette prices are skewed more towards lower prices than are prices under uniform tax systems.

Acknowledgements We would like to thank Anne Chiew Kin Quah for her valuable comments and support.

Contributors The findings and conclusions in this article are those of the authors.

Funding The data collection for the ITC Project is supported by grants R01 CA 100362 and P50 CA111236 (Roswell Park Transdisciplinary Tobacco Use Research Center, and P01 CA138389, R01 CA090955) from the National Cancer Institute of the USA, Robert Wood Johnson Foundation (045734), Canadian Institutes of Health Research (57897, 79551 and 115016), Commonwealth Department of Health and Aging, Canadian Tobacco Control Research Initiative (014578), National Health and Medical Research Council of Australia (265903), the International Development Research Centre (104831-002), the International Development Research Centre (African Tobacco Situational Analysis), New Zealand Health Research Council (06/ 453), New Zealand Ministry of Health, Mexican Consejo Nacional de Ciencia y Tecnologia (Salud-2007-C01-70032), Bloomberg Global Initiative-International Union Against Tuberculosis and Lung Disease, the Chinese Center for Disease Control and Prevention, the French Institute for Health Promotion and Health Education (INPES), the French National Cancer Institute (INCa), Observatoire français des drogues et toxicomanies (OFDT), The Netherlands Organisation for Health Research and Development (ZonMw) (The Netherlands), German Federal Ministry of Health, Dieter Mennekes-Umweltstiftung and Germany Cancer Research Center (DKFZ), Cancer Research UK (C312/A6465), NHS Health Scotland (RE065), Flight Attendants' Medical Research Institute (FAMRI), GlaxoSmithkline (3516601), Pfizer (Ireland), the Korean Ministry of Health and Welfare, the Malaysian Ministry of Health and Thai Health Promotion Foundation. A Senior Investigator Award from the Ontario Institute for Cancer Research and a Prevention Scientist Award from the Canadian Cancer Society Research Institute for the third author and the SILNE Project is funded by the European Commission through FP7

HEALTH-F3-2011-278273.

Competing interests None.
Patient consent Obtained.

Ethics approval All ITC Surveys were conducted with the approval of the Office of Research Ethics Committee at the University of Waterloo, Canada and the respective internal ethics board for each country.

Provenance and peer review Not commissioned; externally peer reviewed.

\section{REFERENCES}

1 IARC. Handbooks of cancer prevention in tobacco control. Vol. 14, International Agency for Research on Cancer, 2011.

2 WHO. WHO technical manual on tobacco tax administration. WHO, 2010.

3 Cnossen S. Tobacco taxation in the European Union, CESifo working paper, No. 1718, 2006.

4 WHO. Increasing tobacco taxation revenue in Egypt. WHO, 2010.

5 Lance PM, Akin JS, Dow WH, et al. Is cigarette smoking in poorer nations highly sensitive to price? Evidence from Russia and China. J Health Econ 2004;23:173-89.

6 White JS, Hu T. How Do Chinese Smokers Respond to Changes in Cigarette Prices? Working Paper. 2012.

7 Chaloupka FJ, Peck R, Tauras JA, et al. Cigarette Excise Taxation: The Impact of Tax Structure on Prices, Revenues, and Cigarette Smoking. NBER Working Paper 16287. 2010.

8 Nargis N, Fong GT, Chaloupka FJ, et al. (forthcoming). The Choics of Discount Brand Cigaretts: A Comprehensive Analysis of International Tobacco Control (ITC) Surveys in Canada and the United States (2002-05). Tobacco Control Supplement 2013.

9 Sobel RS, Garrett TA. Taxation and product quality: new evidence from generic cigarettes. J Political Econ 1997;105:880-7.

10 Hyland A, Laux FL, Higbee $C$, et al. Cigarette purchase patterns in four countries and the relationship with cessation: findings from the International Tobacco Control (ITC) Four Country Survey. Tob Control 2006;15(Suppl III):iii59-64.

11 Cummings KM, Hyland $A$, Lewit $E$, et al. Use of discount cigarettes by smokers in 20 communities in the United States, 1988-1993. Tob Control 1997:6:S25-30.

12 Cummings $\mathrm{KM}$, Hyland $\mathrm{A}$, Lewit $\mathrm{E}$, et al. Discrepancies in cigarette brand sales and adult market share: are new teen smokers filling the gap? Tob Control 1997;6: S38-43.

13 Tsai YW, Yang CL, Chen CS, et al. The effect of Taiwan's tax-induced increases in cigarette prices on brand-switching and the consumption of cigarettes. Health Econ 2005; 14:627-41

14 Li Q, Hyland A, Fong GT, et al. Use of less expensive cigarettes in six cities in China: findings from the International Tobacco Control (ITC) China Survey. Tob Control 2010;19(Suppl 2):i63-68.

15 Kostova D, Chaloupka FJ, Yurekli A, et al. A Cross-country Analysis of Cigarette Prices and Affordability: Evidence from the Global Adult Tobacco Survey. Working Paper, 2012

16 Chaloupka FJ, Kostova D, Shang C. Cigarette excise tax structure and cigarette prices - evidence from the Global Adult Tobacco Survey. Working paper, 2013.

17 Merriman D. The micro-geography of tax avoidance: evidence from littered cigarette packs in Chicago. Am Econ J: Economic Policy 2010;2:61-84.

18 Guindon E, Chaloupka FJ, Fong GT, et al. (forthcoming). Tax Avoidance and Tax Evasion: Comparison of 15 ITC Project Countries. 2013.

19 Joossens $L$, Merriman $\mathrm{D}$, Ross $\mathrm{H}$, et al. The impact of eliminating the global illicit cigarette trade on health and revenue. Addiction 2010;105:1640-9.

20 Fong GT, Cummings KM, Borland R, et al. The conceptual framework of the International Tobacco Control (ITC) Policy Evaluation Project. Tob Control 2006;15 (Suppl 3):iii3-11.

21 IARC handbooks of cancer prevention, tobacco control, Volume 12: methods for evaluating tobacco control policies. Lyon, France: International Agency for Research on Cancer, 2008

22 Orzechowski \& Walker. Tax burden on Tobacco. Historical Compilation, Vol. 46 2011. 